\title{
Microwave Drying Characteristics and Drying Quality Analysis of Corn in China
}

\author{
Haili Liu *, Haoyu Liu, Heyun Liu, Xu Zhang, Qingchao Hong, Wang Chen and Xi Zeng
}

check for updates

Citation: Liu, H.; Liu, H.; Liu, H.; Zhang, X.; Hong, Q.; Chen, W.; Zeng, X. Microwave Drying Characteristics and Drying Quality Analysis of Corn in China. Processes 2021, 9, 1511. https://doi.org/ $10.3390 /$ pr9091511

Academic Editor: Nuno Graça

Received: 2 August 2021

Accepted: 23 August 2021

Published: 26 August 2021

Publisher's Note: MDPI stays neutral with regard to jurisdictional claims in published maps and institutional affiliations.

Copyright: (c) 2021 by the authors. Licensee MDPI, Basel, Switzerland. This article is an open access article distributed under the terms and conditions of the Creative Commons Attribution (CC BY) license (https:// creativecommons.org/licenses/by/ $4.0 /)$.
School of Energy and MechanicaFl Engineering, Hunan University of Humanities, Science and Technology, Loudi 417000, China; lhy3034986762021@126.com (H.L.); changsha7298@126.com (H.L.); zhangxu6398@126.com (X.Z.); hqc421594095@163.com (Q.H.); 3323@huhst.edu.cn (W.C.); zx199077@163.com (X.Z.)

* Correspondence: liuhaili@huhst.edu.cn
Abstract: To identify the microwave drying characteristics of corn, microwave drying tests were conducted on corn. By taking the moisture content, drying rate, and drying temperature as indices, this research revealed the effects of different microwave powers and loads on the microwave drying characteristics of corn. Moreover, energy consumption and quality of dried corn were analysed under different drying conditions. The results demonstrate that microwave drying has significant energy-saving effects. The energy consumption by microwave drying is less than 0.3 times that used by electrothermal drying under the same load. Both microwave power and load exert significant influences on drying characteristics. Higher microwave power results in a greater average drying rate, wherein shorter periods of time are required to reach the maximum drying rate and higher temperatures of the corn. However, the load shows the opposite tendency. The smaller the load, the higher the temperature of the corn in the early stage of drying. However, as drying continues, the temperature curve changes significantly, and the temperature rises with the increase in load in the later stage of drying. In consideration of energy consumption and dried quality, the load of corn should be increased as appropriate, and the microwave intensity should be limited to no higher than $0.7 \mathrm{~W} / \mathrm{g}$ in the experiment.

Keywords: microwave drying; corn; energy consumption of drying; drying quality

\section{Introduction}

China is a large grain producer. According to statistics [1], the total grain output in China was $6.5789 \times 10^{8}$ tons in 2018, in which output of cereal grains reached $6.1019 \times 10^{8}$ tons; however, the annual grain loss caused by mildew in China ranges from $0.87 \%$ to $1.88 \%$, accounting for $24.72 \%$ to $29.22 \%$ of total losses [2]. Properly reducing moisture content in grain can reduce loss of grains caused by mildew.

At present, the techniques commonly used for drying grain include hot-air drying, freeze drying, and microwave drying [3-5]. Of these techniques, microwave drying only works on polar molecules and is very popular due to its advantages, such as fast drying speed, lower energy consumption, and ease of control [6-10]. Hemis et al. [11,12] studied microwave drying of wheat, soybean and canola seeds, and established a new coupling model. However, in the process of drying research, we should not only pay attention to the drying rate and energy consumption, but also pay attention to the quality of the drying product. In the grain-drying process, different drying methods have different effects on taste and nutrition maintenance of grain [13]. Researchers have conducted a great amount of work on grain quality in microwave drying. Smith et al. [14] studied the effects of microwave power and drying time on surface lipid content, protein content, and the final viscosity of rice. Olatunde et al. [15] analyzed the effects of microwave drying on rice moisture removal, milled rice characteristics, and energy requirements, and concluded that the microwave energy should be $450-600 \mathrm{~kJ} / \mathrm{kg}$ in order to maintain the quality of 
rice. Shen et al. [16] investigated the effects of microwave drying on visual color and gamma-aminobutyric acid (GABA) of germinated brown rice (GBR) and found that a microwave intensity of 3-4 W/g is suitable. Yuan et al. [17] researched the influence of different microwave conditions on water migration, quality, lipase activity and the internal structure of rice, and determined that the optimum microwave treatment conditions are a microwave intensity of $1.29 \mathrm{~W} / \mathrm{g}$ and a drying temperature of $60^{\circ} \mathrm{C}$. In order to reduce the drying temperature and better maintain the nutritional components of grains, modified microwave drying methods, such as microwave vacuum drying, are often used in grain drying $[5,18]$. However, compared with microwave drying, microwave vacuum drying has the disadvantages of long drying time, expensive equipment and high operation cost.

Corn is an annual plant which is not only grown for people to eat, but also can be made into high-quality feed for livestock [19]. As a main grain, corn is second only to wheat and rice in yield [20]. China is the second largest maize producer in the world, accounting for more than $20 \%$ of the world's total corn output. Researchers have, previously, conducted a series of studies on corn drying. Nourmohamadi-Moghadami et al. [21] studied the drying behavior of corn in a hot air-infrared dryer. They reported on the effects of inlet air temperature, infrared radiation intensity, and modes of the drying bed on moisture variation during drying process. Abasi et al. [22] investigated the effects of drying air temperature on the mechanical properties of corn kernels. They discovered that kernel deformation at the rupture point increases by $12 \%$ as the temperature increases from $40{ }^{\circ} \mathrm{C}$ to $70{ }^{\circ} \mathrm{C}$; however, values of force, stress, toughness, and modulus of elasticity of corn decreased on average by $21 \%, 26 \%, 36 \%$ and $38 \%$, respectively. In fact, like other grains, microwave drying conditions not only affect the drying characteristics of corn, but also have important effects on the drying quality of corn. Bualuang et al. [23] reported that $300 \mathrm{~W}$ was the most suitable drying condition; germinated maize had the highest nutritive value and antioxidant values under this condition. In fact, the moisture content, physical properties (such as hardness, bulk density, etc.) and nutritional properties (protein content and starch content) of corn in various regions are different, and their drying characteristics are also different. However, there are few reports on microwave drying of corn in China. In addition, crack rate and starch content are important indices of corn drying quality; however there are seldom researches about the effects of microwave drying conditions on these indices.

This study mainly investigated the influences of microwave power and load on the drying characteristics of corn. In addition, the energy consumption and quality of dried corn (crack rate and starch content) under different drying conditions were analysed to provide a theoretical basis for the drying process of corn in the future.

\section{Materials and Methods}

\subsection{Test Materials}

In this study, Wannuo 2000 corn samples were used and stored in a refrigerator for later use. The moisture content in corn kernels was determined to be $54.56 \%$ (w.b.) based on the ISO 6540-1980 standard.

\subsection{Test Equipment}

\subsubsection{Microwave Drying Equipment}

In this research, the microwave drying equipment was an improved M1-L213B microwave oven produced by Guangdong Midea Kitchen Electric Appliance Manufacture Co., Ltd., Foshan, China. The test system of the microwave drying is shown in Figure 1, which is mainly composed of three parts:

(1) A microwave oven. The M1-L213B microwave oven worked at a frequency of $2450 \pm 50 \mathrm{~Hz}$ and a voltage of $220 \mathrm{~V}(1 \pm 10 \%)$. A magnetron was installed in the microwave oven, and the rated input power and output power were $1150 \mathrm{~W}$ and $700 \mathrm{~W}$, respectively. The cavity was a cuboid measuring $315 \times 325 \times 202 \mathrm{~mm}$; 
(2) A test system. The mass of corn was measured by a JD2000-2 precision electronic balance with a precision of $0.01 \mathrm{~g}$ and a measuring range of $1000 \mathrm{~g}$, which was developed by Shenyang Longteng Electronic Co., Ltd., Shenyang, China. The temperature was measured by utilising an ABSD-01A-WB on-line infrared thermometer developed by Shandong Gelin Electronic Technology Co., Ltd., Jinan, China, whose precision was $\pm 1{ }^{\circ} \mathrm{C}$ and which had a measurement range from $0{ }^{\circ} \mathrm{C}$ to $500{ }^{\circ} \mathrm{C}$.

(3) A data acquisition system. By connecting the infrared thermometer and electronic balance with a computer, the mass of materials during drying was monitored and recorded in real time by employing data acquisition software.

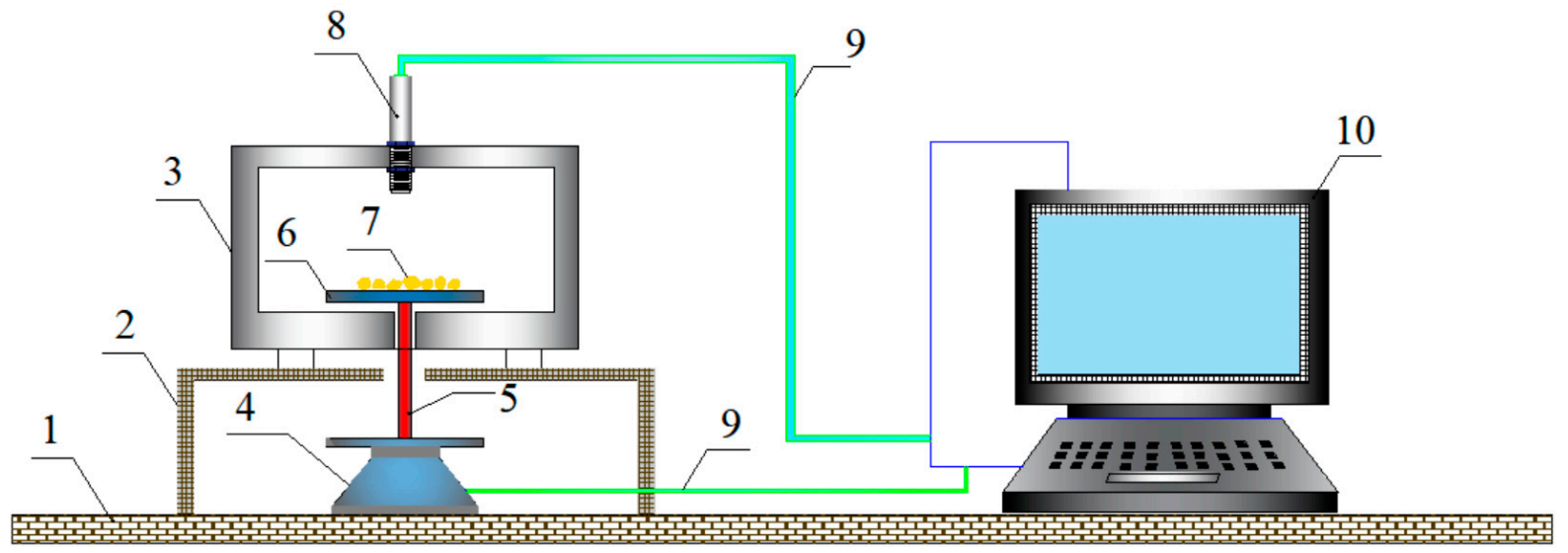

Figure 1. Microwave drying system of corn. 1-Test bench; 2-Bearing; 3-Microwave oven; 4-Electronic balance; 5-Stents; 6-Tray; 7-Corn; 8-Infrared thermometer; 9-Cable; 10-Computer.

\subsubsection{Electrothermal Drying Equipment}

An SFA-3 digital-display air-blast electrothermal drying oven produced by Shanghai Shibo Industrial Co., Ltd., Shanghai, China. was adopted. The mass test system and data acquisition system were the same as those used in the microwave drying equipment.

\subsection{Test Methods and Indices}

\subsubsection{Test Methods}

For the microwave drying test of corn, a certain amount of corn was weighed on the electronic balance and spread on a drying tray. The data acquisition system was set to collect data every minute. When the moisture content of the corn reached $13 \%$ (w.b.), drying was stopped. To measure the temperature of corn, an infrared temperature sensor was used. To ensure accuracy of test data, each group of tests was repeated three times and the average was taken. This project mainly explored the effects of microwave power (the emitted power by the magnetron) and loading amount on drying characteristics of corn. The test scheme is shown in Table 1.

Table 1. Experimental scheme of microwave drying.

\begin{tabular}{ccc}
\hline Number & Microwave Power $(W)$ & Sample Weight $(\mathbf{g})$ \\
\hline 1 & 70 & 60 \\
2 & 70 & 100 \\
3 & 70 & 200 \\
4 & 280 & 100 \\
\hline
\end{tabular}

For the electrothermal drying test of corn, corn $(100 \mathrm{~g})$ was spread on the drying tray and then dried at ventilated air temperatures of $60,80,100,120$ and $140{ }^{\circ} \mathrm{C}$, respectively. Each group of tests was carried out three times and the average value was taken. The specific test scheme of the electrothermal drying is shown in Table 2. 
Table 2. Experimental scheme of electrothermal drying.

\begin{tabular}{ccc}
\hline Number & Drying Temperature $\left({ }^{\circ} \mathbf{C}\right)$ & Sample Weight $(\mathbf{g})$ \\
\hline 1 & 60 & 100 \\
2 & 80 & 100 \\
3 & 100 & 100 \\
4 & 120 & 100 \\
5 & 140 & 100 \\
\hline
\end{tabular}

\subsubsection{Test Indices}

Dry-basis moisture content $(M)$ was determined by the following equation:

$$
M_{t}=\frac{m_{t}-m_{d}}{m_{d}} \times 100 \%
$$

where $M_{t}, m_{t}$ and $m_{d}$ indicate the dry-basis moisture content of the materials at time $t$, the mass of the materials at time $t$, and the mass of dried materials, respectively.

Drying rate $(D R)$ was determined by the following equation:

$$
D R=\frac{d M_{t}}{d t}
$$

Temperature $(T)$ of the materials $\left({ }^{\circ} \mathrm{C}\right)$ was measured using the on-line infrared temperature sensor or thermocouple.

For energy consumption $(E)$ during drying, an electric energy meter was used to determine the power consumption $E(\mathrm{MJ})$ in each test.

Average power $(\bar{P})$ was determined by the following equation:

$$
\bar{P}=E \times 10^{3} / t
$$

where $\bar{P}, E$ and $t$ denote the average power during drying $(\mathrm{kW})$, total power consumption (MJ) during drying and time (s) taken for drying the materials, respectively.

Crack rate was assessed by observing cracks with a magnifiying glass after the samples undergoing different drying conditions were cooled to room temperature. If the length of cracks on corns was greater than half the corn length, they were regarded as cracked corns [24]. The average crack rates calculated from the three groups of samples under each drying condition were taken as the test results. The rate of cracking of corn was detected by a DM4 Solan electronic magnifying glass produced by Yukang Trading Co., Ltd. in Yiwu City, Zhejiang Province, China.

Starch content was assessed by virtue of the polarimeter; the samples under different drying conditions were measured and the average starch contents calculated from the three groups of samples under each drying condition were taken as the test results. A WZZ-2SS automatic polarimeter, developed by Shanghai Tecfront Electronic Technology Co., Ltd., shanghai, China, was used to detect the presence of corn starch.

\section{Results and Discussion}

\subsection{Effects of Microwave Power on Drying Characteristics of Corn}

The curves of the moisture content, drying rate and temperature of corn under different microwave irradiation powers are shown in Figures 2-4. 


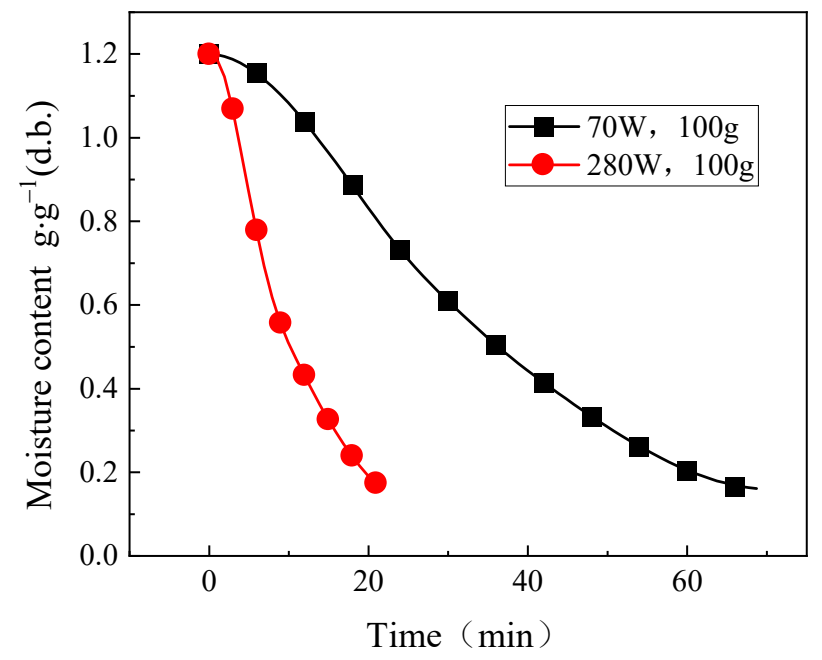

Figure 2. Moisture content of corn under different microwave powers.

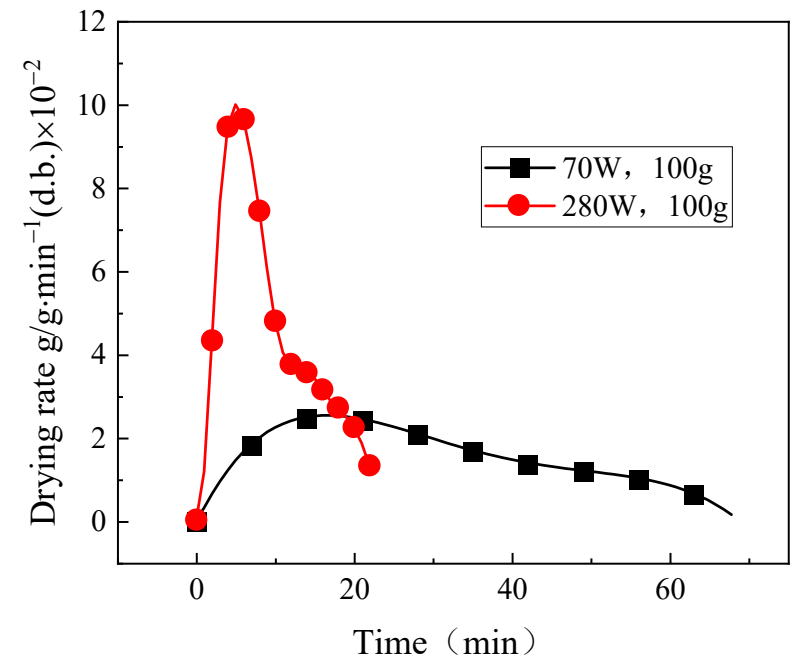

Figure 3. Drying rate of corn under different microwave powers.

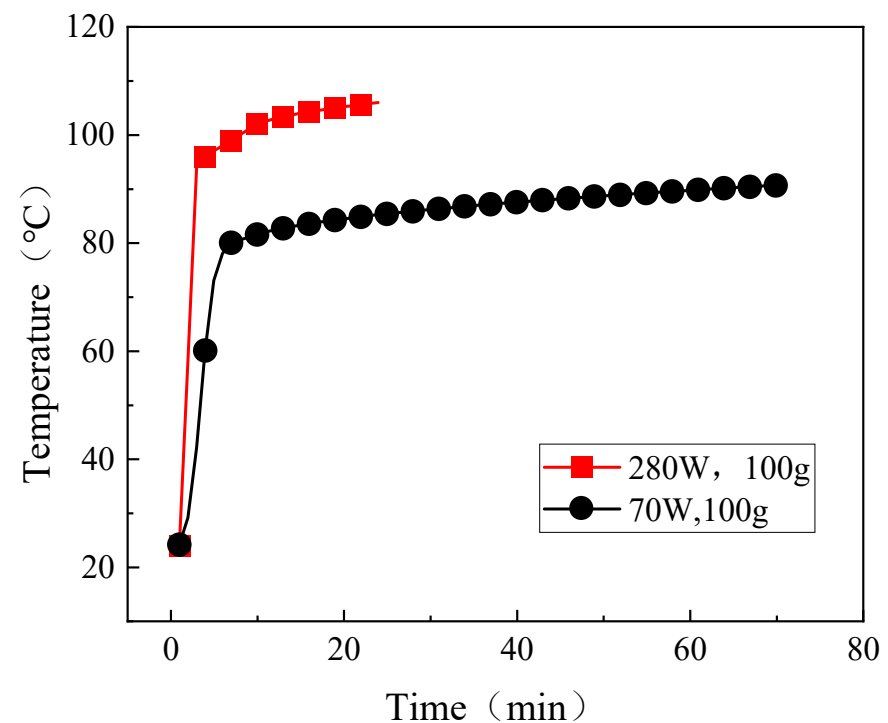

Figure 4. Drying temperature of corn under different microwave powers. 
As shown in Figures 2-4, the effect of microwave power on moisture content and drying rate of corn is similar to that of carrot [25], parsley [26] and wheat seeds [12]. The higher the microwave power, the greater the average drying rate, the less the time required to reach the maximum drying rate, and the higher the temperature of the materials. Under a load of $100 \mathrm{~g}$, at $70 \mathrm{~W}$ and $280 \mathrm{~W}$, it takes $69 \mathrm{~min}$ and $22 \mathrm{~min}$ for the moisture content of corn to be reduced to $13 \%$ (w.b.). Moreover, the average drying rates, separately, are $1.51 \times 10^{-2} \mathrm{~g} / \mathrm{g} \cdot \mathrm{min}^{-1}$ (d.b.) and $4.74 \times 10^{-2} \mathrm{~g} / \mathrm{g} \cdot \mathrm{min}^{-1}$ (d.b.). At $70 \mathrm{~W}$, the maximum drying rate $\left(2.51 \times 10^{-2} \mathrm{~g} / \mathrm{g} \cdot \mathrm{min}^{-1}\right.$ (d.b.) of corn is reached at $17 \mathrm{~min}$, when the drying temperature is $83^{\circ} \mathrm{C}$; at $280 \mathrm{~W}$, the drying rate of corn reaches a maximum of $10.00 \times 10^{-2} \mathrm{~g} / \mathrm{g} \cdot \mathrm{min}^{-1}$ (d.b.) at $5 \mathrm{~min}$. In this case, the drying temperature reaches $97^{\circ} \mathrm{C}$, which is $14^{\circ} \mathrm{C}$ higher than that obtained at $70 \mathrm{~W}$. The energy consumption during microwave drying at $70 \mathrm{~W}$ is $0.468 \mathrm{MJ}$, while that at $280 \mathrm{~W}$ is $0.608 \mathrm{MJ}$; therefore, when a certain mass of corn is dried by microwave irradiation, increasing the applied microwave power can reduce the drying time, albeit with greater energy consumption.

As shown in Figures 2 and 3, the microwave drying process of corn can be divided into three stages from the macroscopic perspective, i.e., the preliminary period (the increasing rate drying period), the first period (the constant rate drying period) and the second drying period (the falling rate drying period), which is in accordance with the microwave drying of most agricultural products [5,26].Using a load of $100 \mathrm{~g}$ of corn, at 70 and $280 \mathrm{~W}$, the preliminary period during the microwave drying of corn are found in the first 12 and $4 \mathrm{~min}$, respectively. In this period, the average drying rates are $1.35 \times 10^{-2}$ and $5.65 \times 10^{-2} \mathrm{~g} / \mathrm{g} \cdot \mathrm{min}^{-1}$ (d.b.), respectively. As shown in Figure 4 , the temperature of the corn samples rises rapidly and the average heating rates reach 4.86 and $18.00{ }^{\circ} \mathrm{C} / \mathrm{min}$ during the preliminary period, respectively. This indicates that in the preliminary period of microwave drying, water molecules in corn vibrate rapidly under the action of microwaves, resulting in the generation of frictional heat. The internal temperatures of the samples increase rapidly, and a temperature gradient between the air in the drying chamber and samples is generated, which encourages moisture inside the corn to spread outwards [27-30]. Hence, the more powerful the microwave irradiation, the faster the drying process. The first period during the microwave drying of corn is found between 12 to 22 and 4 to $7 \mathrm{~min}$ and the average drying rates are $2.57 \times 10^{-2}$ and $9.46 \times 10^{-2} \mathrm{~g} / \mathrm{g} \cdot \mathrm{min}^{-1}$ (d.b.), respectively. In this drying period, the heating rate of the materials is slow, with averages of 0.26 and $6.67^{\circ} \mathrm{C} / \mathrm{min}$. Moreover, the drying rate tends to be stable, which occurs because the speed of water migration inside the corn becomes gradually lower than that of water evaporation from the surface of corn. At $280 \mathrm{~W}$, the first period is very short. This is because the higher the microwave intensity, the more microwave energy is absorbed by water molecules in corn, which leads to a faster temperature rise and accelerated evaporation such that the first period shortens. The second period during the microwave drying of corn is found between 22 to 69 and 7 to $22 \mathrm{~min}$, respectively, in which the average drying rates are $1.33 \times 10^{-2}$ and $3.55 \times 10^{-2} \mathrm{~g} / \mathrm{g} \cdot \mathrm{min}^{-1}$ (d.b.), respectively. In this period, the temperatures of the materials tend to stabilise at about 90 and $105^{\circ} \mathrm{C}$, respectively, while the drying rate decreases. This is due to the gradual decrease of the microwave absorption ability of corn, which occurs concomitantly with the decrease of water content [31,32].

\subsection{The Effects of Load on the Microwave Drying Characteristics of Corn}

The curves of the moisture content, drying rate, and temperature of corn under different loads thereof are shown in Figures 5-7.

As demonstrated in Figures 5 and 6, the influence of loading on the moisture content and the drying rate of corn during microwave drying were similar to influences seen in carrot [25]. Under the same microwave power, the greater the load, the slower the average drying rate, such that it takes more time to reach the maximum drying rate and leads to a smaller maximum drying rate. At $70 \mathrm{~W}$, when the load is 60,100 , and $200 \mathrm{~g}$, the drying time is 44,69 , and $95 \mathrm{~min}$, respectively; furthermore, the average drying rates are $2.37 \times 10^{-2}$, $1.51 \times 10^{-2}$, and $1.10 \times 10^{-2} \mathrm{~g} / \mathrm{g} \cdot \mathrm{min}^{-1}$ (d.b.), respectively. In addition, the maximum 
drying rates are $3.40 \times 10^{-2}, 2.51 \times 10^{-2}$, and $1.62 \times 10^{-2} \mathrm{~g} / \mathrm{g} \cdot \mathrm{min}^{-1}$ (d.b.) and the time required to reach the maximum drying rate is 14,17 , and $23 \mathrm{~min}$, respectively. As shown in Figure 7 , the heating of the materials presents different trends with changes in the load. In the initial stage of drying, the smaller the load, the higher the temperature. As drying continues, the temperature, under a larger load, gradually exceeds that under a smaller load. At $7 \mathrm{~min}$, the temperature under a load of $100 \mathrm{~g}$ exceeds that under a load of $60 \mathrm{~g}$. At $8 \mathrm{~min}$, the temperature under a load of $200 \mathrm{~g}$ is higher than that under $60 \mathrm{~g}$; however, at $12 \mathrm{~min}$, the temperature under a load of $200 \mathrm{~g}$ is higher than that under a load of $100 \mathrm{~g}$. Under loads of 60,100 , and $200 \mathrm{~g}$, the final temperatures are 79,90 , and $95^{\circ} \mathrm{C}$, respectively. The main reason for this is as follows: in the initial stage, the moisture content in the materials is high, which confers a stronger ability to absorb microwave energy. The smaller the load, the greater the energy absorbed per unit mass of material, so the temperature rises faster. Meanwhile, as the drying process continues, the smaller the load, the lower the moisture content and the weaker the ability to absorb microwave energy, so the heating rate also commences more slowly. This causes the temperature of the materials to increase with increased load soon afterwards.

Table 3 shows energy consumption during the microwave drying of corn under different loads. With increasing load, the energy consumption increases, while energy consumption per unit mass decreases, which is similar to trends seen in carrot [25]. At $70 \mathrm{~W}$, the energy consumption per unit mass at a load of $200 \mathrm{~g}$ is only $62.59 \%$ and $70.77 \%$ of those under loads of $60 \mathrm{~g}$ and $100 \mathrm{~g}$. Therefore, in the drying process, the load can be increased as appropriate.

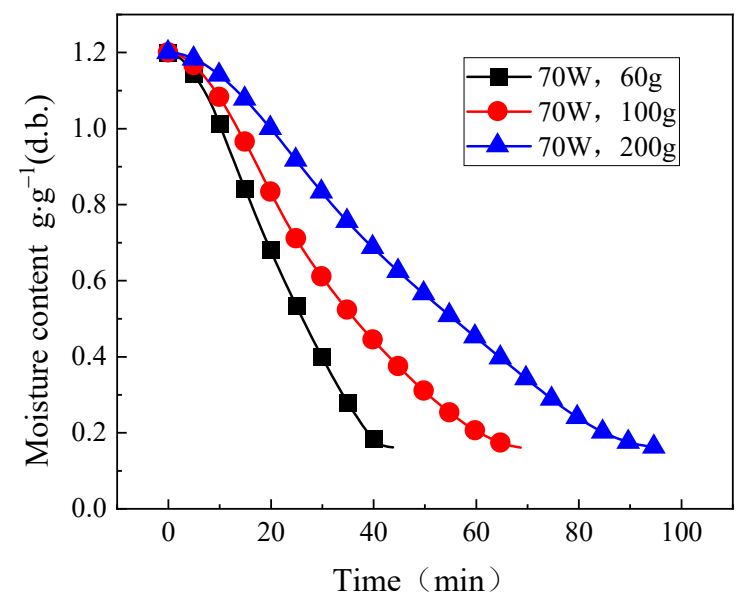

Figure 5. Moisture content of corn with different loads.

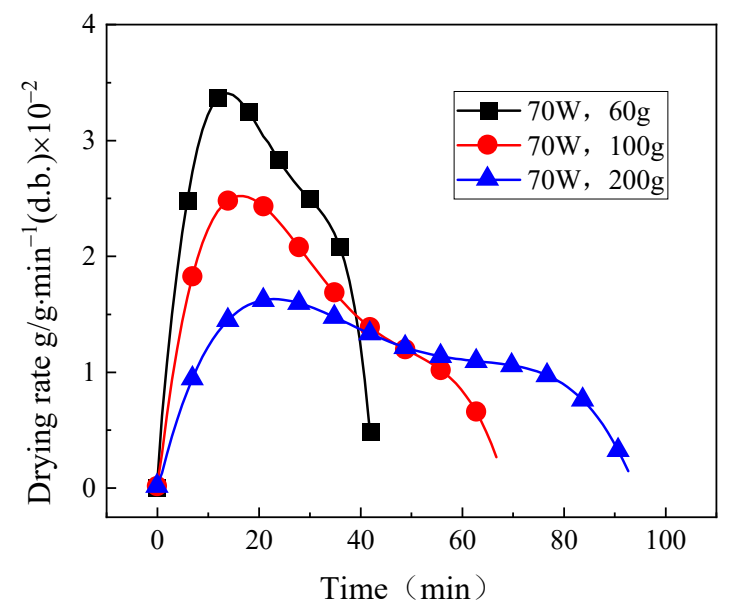

Figure 6. Microwave drying rate of corn with different loads. 


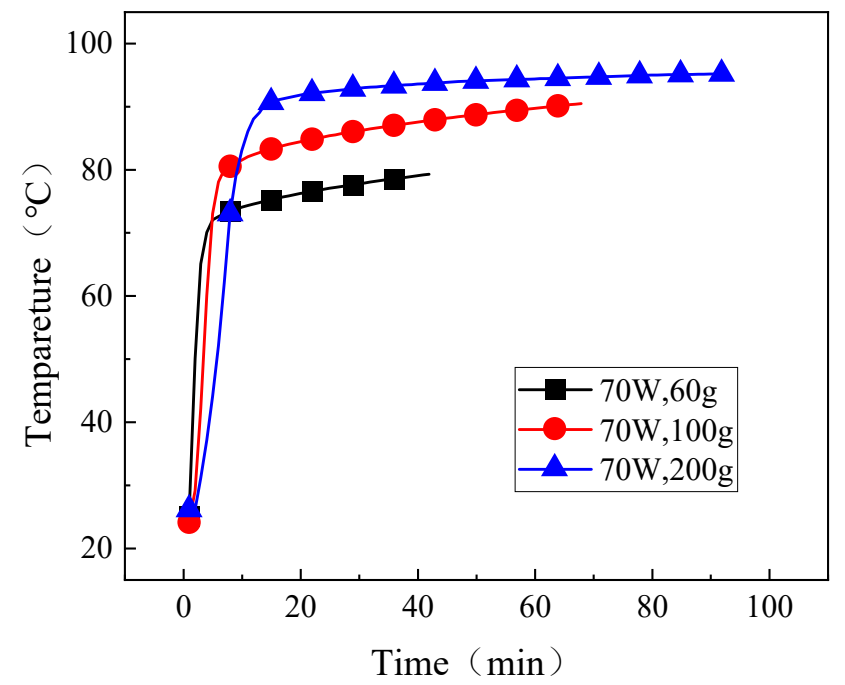

Figure 7. Microwave drying temperature of corn with different loads.

Table 3. Microwave drying energy consumption of corn in different loads.

\begin{tabular}{cccc}
\hline Load (g) & Drying Time (min) & $\begin{array}{c}\text { Energy } \\
\text { Consumption (MJ) }\end{array}$ & $\begin{array}{c}\text { Energy Consumption Per } \\
\text { Unit Mass (MJ/kg) }\end{array}$ \\
\hline 60 & $44 \pm 1$ & $0.317 \pm 0.007$ & $5.28 \pm 0.108$ \\
100 & $69 \pm 2$ & $0.468 \pm 0.013$ & $4.68 \pm 0.147$ \\
200 & $95 \pm 2$ & $0.662 \pm 0.015$ & $3.31 \pm 0.073$ \\
\hline
\end{tabular}

\subsection{Comparison between Microwave Drying and Electrothermal Drying of Corn}

In the same way, $100 \mathrm{~g}$ of corn was selected and dried electrothermally at 60,80 , 100,120 , and $140{ }^{\circ} \mathrm{C}$. The moisture content and drying rates of microwave drying and electrothermal drying are illustrated in Figures 8 and 9.

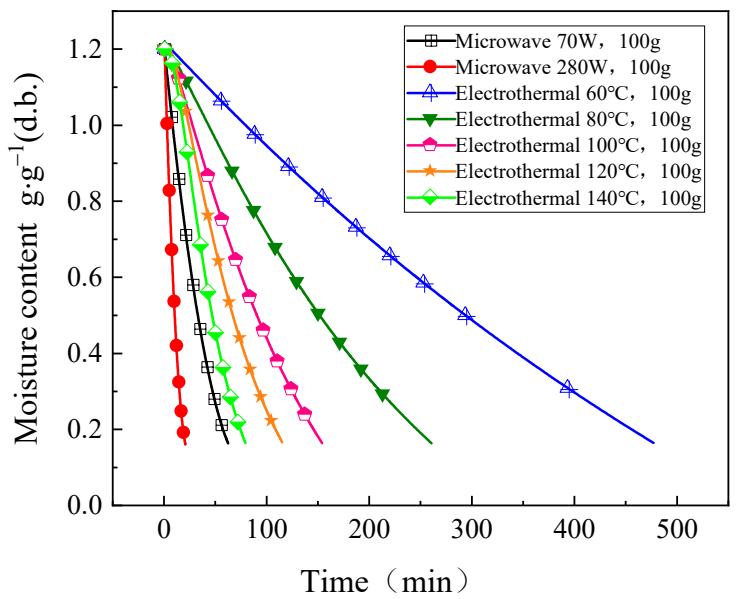

Figure 8. Comparison of moisture content curves between microwave drying and electrothermal drying. 


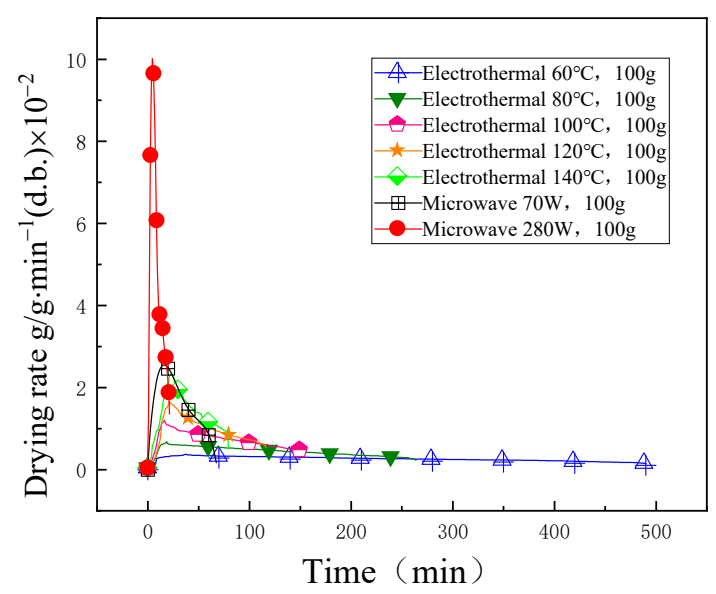

Figure 9. Comparison of drying rate between microwave drying and electrothermal drying.

Figures 8 and 9 show that microwave drying is much faster than electrothermal drying. Even if electrothermal drying is performed at a high temperature of $140{ }^{\circ} \mathrm{C}$, it takes $78 \mathrm{~min}$, which is 1.13 and 3.55 times longer than drying under microwave powers of $70 \mathrm{~W}$ and $280 \mathrm{~W}$. Its maximum drying rate is $2.31 \times 10^{-2} \mathrm{~g} / \mathrm{g} \cdot \mathrm{min}^{-1}$ (d.b.), which is 0.92 and 0.23 times that of the maximum rate during microwave drying at $70 \mathrm{~W}$ and $280 \mathrm{~W}$, respectively. This is mainly because during microwave drying, the internal temperature of the materials is high and the direction of heat conduction is consistent with that of moisture diffusion, which is conducive to moisture evaporation $[15,23]$.

The energy consumptions using different drying methods are shown in Table 4. As shown in Table 4, microwave drying has obvious energy-saving effects. The energy consumption during microwave drying at $70 \mathrm{~W}$ is $0.108,0.186,0.113,0.090$, and 0.093 times that of electrothermal drying at $60,80,100,120$, and $140{ }^{\circ} \mathrm{C}$, respectively. The average power during microwave drying at $280 \mathrm{~W}$ is close to that of electrothermal drying at $100{ }^{\circ} \mathrm{C}$, while the latter is 6.80 times that of the former in terms of energy consumption. Chua [6] and Pratap Singh [18] also obtained similar results. The main reason is that microwaves only act on polar molecules, so the heating efficiency is increased, and the energy loss is lower $[33,34]$.

Table 4. Comparison of energy consumption between microwave drying and electrothermal drying.

\begin{tabular}{ccccc}
\hline Number & Drying Conditions & $\begin{array}{c}\text { Energy } \\
\text { Consumption } \boldsymbol{E} \\
\mathbf{( M J )}\end{array}$ & $\begin{array}{c}\text { Time } \boldsymbol{t} \\
(\mathbf{m i n})\end{array}$ & $\begin{array}{c}\text { Average Power } \overline{\boldsymbol{P}} \\
(\mathbf{k W})\end{array}$ \\
\hline 1 & Electrothermal, $60^{\circ} \mathrm{C}$ & $4.320 \pm 0.147$ & $478 \pm 16$ & $0.151 \pm 0.005$ \\
2 & Electrothermal, $80^{\circ} \mathrm{C}$ & $2.520 \pm 0.112$ & $267 \pm 12$ & $0.157 \pm 0.007$ \\
3 & Electrothermal, $100^{\circ} \mathrm{C}$ & $4.140 \pm 0.137$ & $168 \pm 6$ & $0.411 \pm 0.014$ \\
4 & Electrothermal, $120^{\circ} \mathrm{C}$ & $5.220 \pm 0.155$ & $110 \pm 3$ & $0.791 \pm 0.023$ \\
5 & Electrothermal, $140^{\circ} \mathrm{C}$ & $5.040 \pm 0.148$ & $78 \pm 2$ & $1.077 \pm 0.032$ \\
6 & Microwave, $70 \mathrm{~W}$ & $0.468 \pm 0.014$ & $69 \pm 2$ & $0.115 \pm 0.004$ \\
7 & Microwave, $280 \mathrm{~W}$ & $0.608 \pm 0.018$ & $22 \pm 1$ & $0.460 \pm 0.014$ \\
\hline
\end{tabular}

\section{Comparison of Qualities of Corn after Microwave Drying and Electrothermal Drying}

The crack rate and starch content are important indices used to measure quality of dried grain [35]. Cracks are induced by stress in the process of cereal grain drying and dehydration. Grain with stress cracks will continue to increase the degree of cracking in subsequent mechanical processing, resulting in the exposure of internal starch and enhancement of water absorption, so that the dried quality decreases. Starch is the most abundant organic matter in corn. If it is kept at a high temperature for a long time, it will be gelatinised, which changes the hardness, quality, and colour of the corn. As illustrated in Figures 10 and 11, when the microwave power is enhanced or electrothermal temperature 
is increased, the rate of cracking of corn increases and the starch content decreases. Under a load of $100 \mathrm{~g}$, a high dried quality can be obtained by electrothermal drying at $60^{\circ} \mathrm{C}$ and $80^{\circ} \mathrm{C}$ and by microwave drying at $70 \mathrm{~W}$. Their rates of cracking are $21.975 \%, 27.305 \%$, and $31.268 \%$ and the starch contents are $71.16 \%, 68.43 \%$, and $61.32 \%$, respectively. Therefore, when microwave drying is performed, considering the crack rate and starch content for measuring quality, the microwave intensity cannot be too strong, and the intensity of the microwave drying should not exceed $0.7 \mathrm{~W} / \mathrm{g}$ in the experiment.

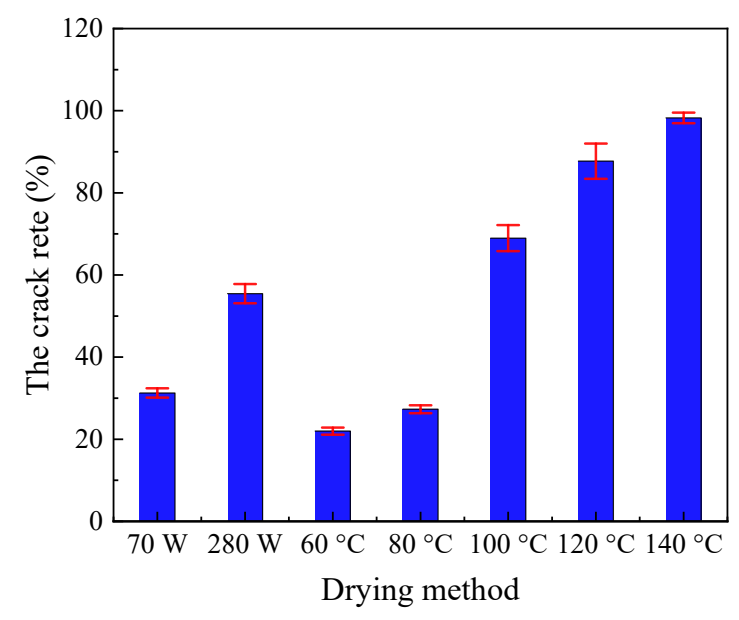

Figure 10. Comparison of crack rates in different drying methods.

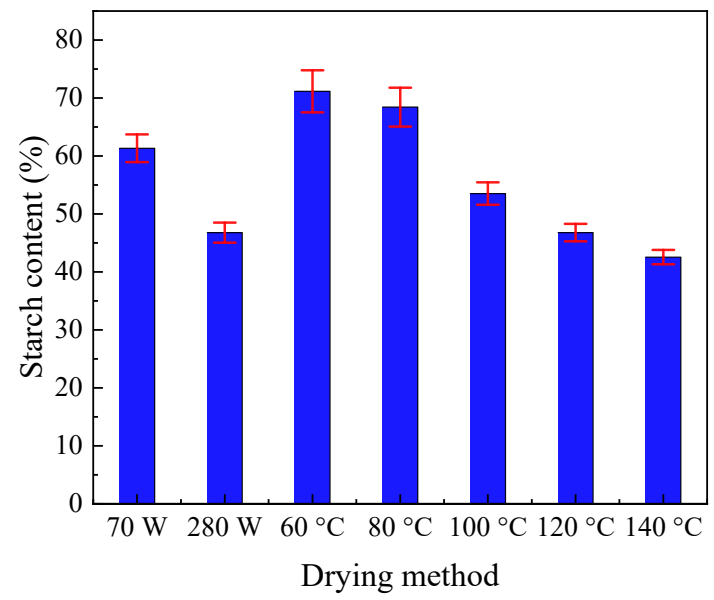

Figure 11. Comparison of starch content in different drying methods.

\section{Conclusions}

To explore the microwave drying characteristics of corn, drying tests were conducted on corn under different loads and microwave irradiation powers and a comparative test was conducted with electrothermal drying. The following conclusions are drawn:

(1) Macroscopically, the microwave drying stage of corn can be divided into the increasing rate drying period, the constant rate drying period and the falling rate drying period. In different periods, corn shows different drying characteristics. In the increasing rate drying period, the drying rate and heating rate increase rapidly. In the constant rate drying period, the drying rate tends to be stable, while the temperature increases slowly. In the falling rate drying period, the drying rate reduces slowly, and the temperature tends to be stable;

(2) Microwave power and load affect the drying characteristics of corn such that the higher the microwave power, the greater the average drying rate, which leads to a shorter period of time being required to reach the maximum drying rate and higher temperature 
of corn. However, the load shows the opposite influence. In the initial stage of drying, the smaller the load, the higher the temperature of the corn. As drying continues, the temperature of the corn when drying a larger load becomes much higher than that under a smaller load. The phenomenon whereby the temperature of the corn increases with the increase of the load arises at a later stage;

(3) Microwave drying is much faster than electrothermal drying. Under the same load, the time taken for electrothermal drying at $140{ }^{\circ} \mathrm{C}$ is 1.13 and 3.55 times that under microwave drying at $70 \mathrm{~W}$ and $280 \mathrm{~W}$. Microwave drying confers significant energy-saving effects. Microwave drying at $280 \mathrm{~W}$ requires a similar average power to electrothermal drying at $100{ }^{\circ} \mathrm{C}$; however, in terms of energy consumption, the latter requires 6.80 times that of the former;

(4) Considering energy consumption during drying and dried quality, the load can be increased within a certain range and the intensity of microwave drying should not exceed $0.7 \mathrm{~W} / \mathrm{g}$ in the experiment. These results are useful in the selection of optimum drying conditions during microwave drying of corn.

In order to further expand the research findings of this paper, it is necessary to establish drying kinetic models and calculate the drying kinetics parameters. In addition, the surface color, nutritional content and rehydration parameters of corn also need testing under different drying conditions.

Author Contributions: Data curation, Q.H.; investigation, H.L. (Haili Liu), H.L. (Haoyu Liu) and X.Z. (Xu Zhang); methodology, H.L. (Heyun Liu) and W.C.; project administration, H.L. (Heyun Liu); writing-original draft, H.L. (Haili Liu); writing-review \& editing, X.Z. (Xi Zeng). All authors have read and agreed to the published version of the manuscript.

Funding: This research was funded by the Hunan Provincial Natural Science Foundation of China (2021JJ50132) and the Hunan Province Graduate Scientific Research and Innovation Project of China (CX20201189).

Institutional Review Board Statement: Not applicable.

Informed Consent Statement: Not applicable.

Data Availability Statement: All data used to support the findings of this study are included within the article.

Conflicts of Interest: The authors declare that they have no conflict of interest regarding the publication of this paper.

\section{Nomenclature}

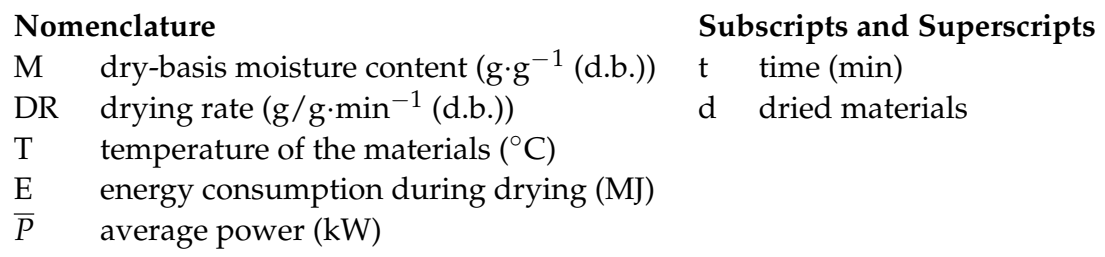

\section{References}

1. Minmin, J.; Guixiang, C.; Chaosai, L.; Wenlei, L.; Zhijing, Z. Effects of moisture content on elastic-plastic properties of bulk wheat. Trans. Chin. Soc. Agric. Eng. 2020, 36, 245-251.

2. Zhang, L.; Liu, P. Review of research status of crop mildew. Grain Sci. Technol. Econ. 2020, 45, 89-90.

3. Monteiro, R.L.; Link, J.V.; Tribuzi, G.; Carciofi, B.A.M.; Laurindo, J.B. Microwave vacuum drying and multi-flash drying of pumpkin slices. J. Food Eng. 2018, 232, 1-10. [CrossRef]

4. Wang, W.; Zhang, S.; Pan, Y.; Tang, Y.; Chen, G. Wave-absorbing material aided microwave freeze-drying of vitamin C solution frozen with preformed pores. Dry. Technol. 2020, 1-14. [CrossRef]

5. Cao, X.; Zhang, M.; Fang, Z.; Mujumdar, A.S.; Jiang, H.; Qian, H.; Ai, H. Drying kinetics and product quality of green soybean under different microwave drying methods. Dry. Technol. 2017, 35, 240-248. [CrossRef] 
6. Chua, L.Y.W.; Chua, B.L.; Figiel, A.; Chong, C.H.; Wojdyło, A.; Szumny, A.; Łycko, J. Drying of Phyla nodiflora Leaves: Antioxidant Activity, Volatile and Phytosterol Content, Energy Consumption, and Quality Studies. Processes 2019, 7, 210. [CrossRef]

7. Zhao, P.; Liu, C.; Qu, W.; He, Z.; Gao, J.; Jia, L.; Ji, S.; Ruan, R. Effect of Temperature and Microwave Power Levels on Microwave Drying Kinetics of Zhaotong Lignite. Processes 2019, 7, 74. [CrossRef]

8. Choo, C.O.; Chua, B.L.; Figiel, A.; Jałoszyński, K.; Wojdyło, A.; Szumny, A.; Łyczko, J.; Chong, C.H. Hybrid Drying of Murraya koenigii Leaves: Energy Consumption, Antioxidant Capacity, Profiling of Volatile Compounds and Quality Studies. Processes 2020, 8, 240. [CrossRef]

9. Wang, H.; Liu, D.; Yu, H.; Wang, D.; Li, J. Optimization of Microwave Coupled Hot Air Drying for Chinese Yam Using Response Surface Methodology. Processes 2019, 7, 745. [CrossRef]

10. Thuto, W.; Banjong, K. Investigation of Heat and Moisture Transport in Bananas during Microwave Heating Process. Processes 2019, 7, 545. [CrossRef]

11. Hemis, M.; Gariépy, Y.; Choudhary, R.; Raghavan, V. New coupling model of microwave assisted hot-air drying of a capillary porous agricultural product: Application on soybeans and canola seeds. Appl. Therm. Eng. 2017, 114, 931-937. [CrossRef]

12. Hemis, M.; Choudhary, R.; Watson, D.G. A coupled mathematical model for simultaneous microwave and convective drying of wheat seeds. Biosyst. Eng. 2012, 112, 202-209. [CrossRef]

13. Gürsoy, S.; Choudhary, R.; Watson, D.G. Microwave drying kinetics and quality characteristics of corn. Int. J. Agric. Biol. Eng. 2013, 6, 90 .

14. Smith, D.L.; Atungulu, G.G.; Sadaka, S.; Rogers, S. Implications of microwave drying using $915 \mathrm{MHz}$ frequency on rice physicochemical properties. Cereal Chem. 2018, 95, 211-225. [CrossRef]

15. Olatunde, G.A.; Atungulu, G.G.; Smith, D.L. One-pass drying of rough rice with an industrial $915 \mathrm{MHz}$ microwave dryer: Quality and energy use consideration. Biosyst. Eng. 2017, 155, 33-43. [CrossRef]

16. Shen, L.; Gao, M.; Zhu, Y.; Liu, C.; Wang, L.; Kamruzzaman, M.; Liu, C.; Zheng, X. Microwave drying of germinated brown rice: Correlation of drying characteristics with the final quality. Innov. Food Sci. Emerg. 2021, 70, 102673. [CrossRef]

17. Yuan, J.; Zhao, T.; Ding, C. Effects of microwave treatments on rice quality and lipase activity. Sci. Agric. Sin. 2018, 21, 4131-4142.

18. Pratap Singh, A.; Mandal, R.; Shojaei, M.; Singh, A.; Kowalczewski, P.Ł.; Ligaj, M.; Pawlicz, J.; Jarzębski, M. Novel Drying Methods for Sustainable Upcycling of Brewers' Spent Grains as a Plant Protein Source. Sustainability 2020, 12, 3660. [CrossRef]

19. Jin, X.; Wang, C.; Bi, Q.; Liu, Z.; Zhang, Z. Study on drying characteristics of corn based on 3D model. Int. J. Food Eng. 2020, 16. [CrossRef]

20. Gwirtz, J.A.; Garcia Casal, M.N. Processing maize flour and corn meal food products. Ann. N. Y. Acad. Sci. 2014, 1312, 66-75. [CrossRef]

21. Rahmanian-Koushkaki, H.; Nourmohamadi-Moghadami, A.; Zare, D.; Karimi, G. Experimental and theoretical investigation of hot air-infrared thin layer drying of corn in a fixed and vibratory bed dryer. Eng. Agric. Environ. Food 2017, 10, 191-197. [CrossRef]

22. Abasi, S.; Minaei, S. Effect of Drying Temperature on Mechanical Properties of Dried Corn. Dry. Technol. 2014, 32, 774-780. [CrossRef]

23. Bualuang, O.; Onwude, D.I.; Pracha, K. Microwave drying of germinated corn and its effect on phytochemical properties. J. Sci. Food Agric. 2017, 97, 2999-3004. [CrossRef] [PubMed]

24. Crostack, H.A.; Nellesen, J.; Fischer, G.; Hofmann, M.; Rademacher, H.G.; Tillmann, W. Analysis of Crack Patterns in Drying Corn Starch by in-situ Radiography and X-ray Computer Tomography. Exp. Mech. 2012, 52, 917-932. [CrossRef]

25. Wang, J.; Xi, Y.S. Drying characteristics and drying quality of carrot using a two-stage microwave process. J. Food Eng. 2005, 68, 505-511. [CrossRef]

26. Soysal, Y. Microwave Drying Characteristics of Parsley. Biosyst. Eng. 2004, 89, 167-173. [CrossRef]

27. Hemis, M.; Singh, C.B.; Jayas, D.S. Microwave-Assisted Thin Layer Drying of Wheat. Dry. Technol. 2011, 29, 1240-1247. [CrossRef]

28. Hou, L.; Li, R.; Wang, S.; Datta, A.K. Numerical analysis of heat and mass transfers during intermittent microwave drying of Chinese jujube (Zizyphus jujuba Miller). Food Bioprod. Process. 2021, 129, 10-23. [CrossRef]

29. Qi, S.; Han, J.; Lagnika, C.; Jiang, N.; Qian, C.; Liu, C.; Li, D.; Tao, Y.; Yu, Z.; Wang, L.; et al. Dielectric properties of edible fungi powder related to radio-frequency and microwave drying. Food Prod. Process. Nutr. 2021, 3, 1-13. [CrossRef]

30. Mardaras, J.; Lombraña, J.I.; Villarán, M.C. Effect of the thermal level on the viability of microencapsulated living cells dehydrated by near fluidizing microwave drying. Dry. Technol. 2021, 39, 219-233. [CrossRef]

31. Guo, J.; Zheng, L.; Li, Z. Microwave drying behavior, energy consumption, and mathematical modeling of sewage sludge in a novel pilot-scale microwave drying system. Sci. Total Environ. 2021, 777, 146109. [CrossRef] [PubMed]

32. Kipcak, A.S.; İsmail, O. Microwave drying of fish, chicken and beef samples. J. Food Sci. Technol. 2021, 58, 281-291. [CrossRef] [PubMed]

33. Silva, E.G.; Gomez, R.S.; Gomes, J.P.; Silva, W.P.; Porto, K.Y.N.; Rolim, F.D.; Carmo, J.E.F.; Andrade, R.O.; Santos, I.B.; Sousa, R.A.A.; et al. Heat and Mass Transfer on the Microwave Drying of Rough Rice Grains: An Experimental Analysis. Agriculture 2021, 11, 8. [CrossRef]

34. Boshkova, I.L.; Volgusheva, N.V.; Boshkov, L.Z. Analytical study of temperature field during microwave drying of the material. J. Phys. Conf. Ser. 2020, 1683, 22044. [CrossRef]

35. Zhang, H.; Wang, R.; Wang, J.; Dong, Y. Microwave-assisted synthesis and characterization of acetylated corn starch. Starch-Stärke 2014, 66, 515-523. [CrossRef] 